Research Article

\section{Nebulization as complementary therapy for dogs with respiratory tract infections}

\author{
Stopyra Artur ${ }^{1 *}$, Sobiech Przemyslaw ${ }^{1}$, Pomianowski Andrzej ${ }^{1}$, \\ Zarczynska Katarzyna ${ }^{1}$ and Edyta Kaczorek ${ }^{2}$
}

1Department of Internal Diseases with Clinic, Faculty of Veterinary Medicine, University of Warmia and Mazury in Olsztyn, Olsztyn, Poland

${ }^{2}$ Department of Microbiology and Clinical Immunology, Faculty of Veterinary Medicine, University of Warmia and Mazury in Olsztyn, Olsztyn, Poland

\section{Abstract}

Respiratory tract infections in dogs pose a significant problem and often require prolonged treatment. The effectiveness of pharmacological therapy can be improved through the administration of nebulized compounds to liquidize mucus and promote its evacuation from the respiratory tract. The aim of this study was to evaluate the effectiveness of nebulized $0.9 \%$ $\mathrm{NaCl}$ in dogs with respiratory tract infections. Respiratory functions were assessed based on the results of arterial blood gas analyses, and the patients' clinical status was determined by evaluating the severity of symptoms on a point grading scale. Inhalation of nebulized $0.9 \% \mathrm{NaCl}$ significantly accelerated improvement in the patents' clinical status (normalization of body temperature, decreased cough frequency, decrease/elimination of nasal and ocular discharge, improved appetite) and improved pulmonary gas exchange by reducing partial pressure and total content of carbon dioxide and increasing partial pressure and total content of oxygen in blood.

\section{More Information}

*Address for Correspondence: Stopyra Artur, Department of Internal Diseases with Clinic, Faculty of Veterinary Medicine, University of Warmia and Mazury in Olsztyn, Oczapowskiego 14, 10-957 Olsztyn, Poland, Tel: 0-048-89-524-52-12; Email: astopyra@uwm.edu.pl

Submitted: 05 September 2019

Approved: 03 October 2019

Published: 04 October 2019

How to cite this article: Artur S, Przemysław S, Andrzej P, Katarzyna Z, Kaczorek E. Nebulization as complementary therapy for dogs with respiratory tract infections. Insights Vet Sci. 2019; 3: 030-035.

DOI: dx.doi.org/10.29328/journal.ivs.1001017

ORCiD ID: orcid.org/0000-0001-7018-7286

Copyright: (C) 2019 Artur S, et al. This is an open access article distributed under the Creative Commons Attribution License, which permits unrestricted use, distribution, and reproduction in any medium, provided the original work is properly cited.

Keywords: Dog; Respiratory tract infection; Inhalation; Acid-base equilibrium

Check for updates

\section{Introduction}

Respiratory tract infections in dogs are usually contagious and are caused by bacterial and viral agents [1,2]. Infectious and confounding agents include mycoplasma, streptococci, staphylococci and viruses (canine parainfluenza virus, canine herpesvirus, canine adenovirus type 2). Compromised immunity, infections with commensal pathogens, stress associated with sudden change of environment, parasitic and metabolic diseases, and nutritional deficiencies contribute to respiratory infections [3].

Respiratory infections provoke pathological mechanisms in lung tissue [4,5], including increased secretion of respiratory mucus and edema caused by inflammatory cell infiltration. These processes produce adverse symptoms such as cough (wet and dry, subject to the type of inflammation) and dyspnea caused by airway constriction, mucosal edema and increased secretion of respiratory mucus. The above can increase the thickness of the blood-air barrier in pulmonary alveoli (between capillaries and the alveolar lumen). According to Eleanor, [6], impaired gas exchange increases carbon dioxide concentration and decreases oxygen concentration in the body, which can disrupt metabolic processes and decrease the efficacy of treatment [7]. Kiers, et al. [8] demonstrated that hypoxia also affects the immune system, which can undermine positive treatment outcomes. There are various approaches to improving gas exchange. Steroidal anti-inflammatory drugs are effective, but they deliver immunosuppressive effects that have to be managed with antibacterial drugs, and they disrupt vaccination schedules in young animals. Mucolytic drugs and expectorants cause mucus thinning and increase the output of bronchial secretions. They facilitate the secretion of the fluid fraction of bronchial mucus and water, and they increase mucus volume, which stimulates the response of ciliated epithelium and promotes the evacuation of secretions from the bronchi. However, excessive amounts of mucus can partially "flood" the lungs and compromise gas exchange. Acetylcysteine is one of the few mucolytic drugs that do not increase mucus volume, but only decrease its viscosity [9]. The drug breaks down disulfide bridges in mucopolysaccharides, reduces mucus viscosity and facilitates its evacuation. The administration of nebulized sodium chloride solution at physiological or higher concentrations does not involve the use of drugs with potential adverse side effects, such as digestive 
disturbances, that are not always well tolerated by the patient and are not approved by the owners [10-12]. Inhalation of saline aerosol combined with physical therapy (percussion, encouraging physical exercise) can speed up therapy and reduce pharmacological interventions $[13,14]$. Sudo, et al. [2] reported a decrease in the viscosity of bronchial mucus in dogs administered nebulized dextran-Ringer solution. According to Fernandes and Vanbever [15], and Chow, et al. [16], nebulization is a promising non-invasive method of delivering pharmacological treatments with general systemic effects. In "human medicine" it was used to treat not only pulmonary diseases [17-20] but in pain or neoplasm therapy too $[1,21]$.

\section{Objective of the study}

The objective of this study was to evaluate the efficacy of nebulized sodium chloride solution in dogs with mixed respiratory tract infections as complementary therapy that speeds up convalescence.

\section{Materials and Methods}

\section{Animals}

The experiment was performed on dogs of various breeds, both sexes ( 21 females and 25 males), aged 3 months to 9 years, with body weight of 4 to $35 \mathrm{~kg}$, kept under similar conditions (indoor pets), which were patients of the Department of Internal Diseases at the Faculty of Veterinary Medicine of the University of Warmia and Mazury in Olsztyn. All of the dogs were treated according to Good Clinical Practice rules and regulations of the local ethical committee of animal welfare.

\section{Inclusion criteria}

The inclusion criteria were symptoms of respiratory tract infection: cough (minimum 4 episodes per day), body temperature higher than $39{ }^{\circ} \mathrm{C}$, nasal and/or ocular discharge, dyspnea, decreased appetite, and presence of pathogenic microorganisms in throat and tracheal aspirate cultures (determined by PCR).

\section{Laboratory tests (genetic and blood gas analysis)}

Viral DNA or RNA and bacterial DNA were isolated with the QIAamp cador Pathogen Mini Kit (Qiagen, Hilden, Germany) according to the manufacturer's instructions. The genetic material of the canine parainfluenza virus (CPiV) was detected with the Transcriptor One-Step RT-PCR Kit (Roche Diagnostics, Meylan, France) in the Mastercycler nexus gradient thermal cycler (Eppendorf, Hamburg, Germany). The genetic material of the canine herpesvirus (CHV), canine adenovirus type 2 (CAV2) and Bordetella bronchiseptica was analyzed with the HotStarTaq plus Master Mix Kit (Qiagen, Hilden, Germany) in the Mastercycler nexus gradient thermal cycler (Eppendorf, Hamburg, Germany). Before the collection of respiratory specimens, arterial blood was sampled from the femoral vein into gas-tight glass capillary tubes coated with heparin for blood gas analysis with the use of the
Rapidlab 348 analyzer, including body temperature, blood $\mathrm{pH}$, partial pressure of carbon dioxide $\left(\mathrm{pCO}_{2}\right)$, partial pressure of oxygen $\left(\mathrm{pO}_{2}\right)$, concentration of bicarbonate ions $\left(\mathrm{HCO}_{3}^{-}\right)$, base excess/deficit (BE), oxygen saturation $\left(\mathrm{O}_{2} \mathrm{SAT}\right)$ and total carbon dioxide content $\left(\mathrm{ctCO}_{2}\right)$ in blood on the first day of the experiment and on experimental days 7 and 15 .

\section{Patient's treatment}

All patients were administered amoxicillin with clavulanic acid (subcutaneous dose of $7.0 \mathrm{mg}$ of amoxicillin and 1.75 $\mathrm{mg}$ of clavulanic acid per $20 \mathrm{~kg} \mathrm{BW}$, once daily for 5 days), metamizole (intramuscular injection of $35 \mathrm{mg} / \mathrm{kg} \mathrm{BW}$, administered once daily until fever reduction) and vitamin $\mathrm{C}$ (oral dose of $50 \mathrm{mg} / \mathrm{kg} \mathrm{BW}$, twice a day for 5 days). Chest percussion was performed twice daily to facilitate mucus evacuation. In randomly selected dogs (every other case) that constituted group II, nebulized $0.9 \% \mathrm{NaCl}$ solution was administered with the use of the Tajfun2 MU2 ultrasonic nebulizer. Partly sealed transport cages of the appropriate size were used as nebulization chambers. Nebulization therapy was administered twice a day for 14 days. Every treatment lasted minimum $20-40$ minutes, and $50-150 \mathrm{ml}$ of $0.9 \% \mathrm{NaCl}$ was nebulized, subject to the animal's size. Group I animals did not receive inhalation therapy.

\section{Score health evaluation}

The animals' clinical status was evaluated (on the first day of the experiment and on days 3, 7, 10 and 15) based on body temperature, frequency and severity of cough, nasal/ocular discharge and appetite with the use of a point grading scale: body temperature up to $38.6{ }^{\circ} \mathrm{C}-0$ points, $38.7-38.9^{\circ} \mathrm{C}-1$ point, $39.0-39.3^{\circ} \mathrm{C}-2$ points, above $39.4^{\circ} \mathrm{C}-3$ points; cough episode - none - 0 points, 1-2 episodes per day - 1 point, 3-4 episodes per day - 2 points, 5 and more episodes per day -3 points; cough accompanied by a gag reflex - additional 1 point; nasal/ocular discharge - none - 0 points, clear, serous nasal discharge -1 point, clear, serous nasal and ocular discharge - 2 points, purulent nasal discharge -3 points, purulent nasal and ocular discharge - 4 points; appetite - normal - 3 points, decreased -2 point, decreased by $50 \%$ from baseline -1 points, loss of appetite or very weak appetite -0 points. The results were analyzed statistically by Student's t-test.

\section{Results}

Symptoms of respiratory tract infection were observed in Group I and Group II dogs on the first day of the experiment. According to the information provided by the owners, infection symptoms had persisted for more than 6 days.

\section{Pathogens}

The genetic material of pathogens responsible for respiratory tract infections was detected in throat and tracheal aspirate swabs. Mixed viral and bacterial infections were identified in most patients (Table 1). Infections with exclusively viral etiology were diagnosed in 2 dogs, and infections caused only by bacteria were noted in 3 animals. 
Mixed viral and bacterial infections were identified in 18 dogs from Group I and in 17 animals from Group II. Infections caused by two or three of the identified viruses were diagnosed in the remaining animals. The canine parainfluenza virus was detected in 23 dogs (11 dogs from Group I and 12 dogs from Group II), the canine herpesvirus - in 35 dogs (10 and 15, respectively) and the canine adenovirus - in 4 dogs (2 and 2, respectively). Bordetella bronchiseptica infections were observed in 38 animals.

Table 1: The results of microbiological analyses of respiratory specimens collected from Group I and Group II dogs with symptoms of respiratory tract infection

\begin{tabular}{|c|c|c|c|c|}
\hline \multicolumn{5}{|c|}{ Group I } \\
\hline Dog No. & CPiV & CHV & CAV2 & B. bronchiseptica \\
\hline 1 & negative & positive & negative & positive \\
\hline 3 & negative & positive & negative & positive \\
\hline 5 & negative & positive & negative & positive \\
\hline 7 & negative & positive & negative & negative \\
\hline 9 & positive & negative & negative & positive \\
\hline 11 & positive & negative & negative & positive \\
\hline 13 & positive & positive & positive & negative \\
\hline 15 & positive & negative & negative & positive \\
\hline 17 & positive & positive & negative & negative \\
\hline 19 & positive & positive & negative & negative \\
\hline 21 & negative & positive & negative & negative \\
\hline 23 & positive & positive & negative & positive \\
\hline 25 & negative & positive & negative & positive \\
\hline 27 & negative & positive & positive & negative \\
\hline 29 & negative & positive & negative & positive \\
\hline 31 & positive & positive & negative & positive \\
\hline 33 & negative & positive & negative & positive \\
\hline 35 & negative & positive & negative & positive \\
\hline 37 & negative & positive & negative & positive \\
\hline 39 & positive & positive & negative & positive \\
\hline 41 & positive & positive & negative & positive \\
\hline 43 & negative & positive & negative & positive \\
\hline 45 & positive & positive & negative & positive \\
\hline \multicolumn{5}{|c|}{ Group II } \\
\hline Dog No. & CPiV & $\mathrm{CHV}$ & CAV2 & B. bronchiseptica \\
\hline 2 & negative & positive & negative & positive \\
\hline 4 & negative & positive & negative & positive \\
\hline 6 & negative & positive & negative & positive \\
\hline 8 & negative & positive & negative & positive \\
\hline 10 & positive & negative & negative & positive \\
\hline 12 & positive & negative & positive & positive \\
\hline 14 & positive & positive & negative & positive \\
\hline 16 & positive & negative & negative & positive \\
\hline 18 & positive & negative & negative & positive \\
\hline 20 & positive & positive & negative & positive \\
\hline 22 & negative & negative & negative & positive \\
\hline 24 & positive & positive & negative & positive \\
\hline 26 & negative & negative & negative & positive \\
\hline 28 & positive & positive & negative & positive \\
\hline 30 & negative & negative & negative & positive \\
\hline 32 & negative & positive & positive & positive \\
\hline 34 & negative & positive & negative & positive \\
\hline 36 & positive & positive & negative & negative \\
\hline 38 & positive & positive & negative & positive \\
\hline 40 & negative & positive & negative & negative \\
\hline 42 & negative & positive & negative & positive \\
\hline 44 & positive & positive & negative & negative \\
\hline 46 & positive & negative & negative & positive \\
\hline
\end{tabular}

\section{Clinical symptoms - body temperature}

The severity of clinical symptoms in the evaluated patients is presented in Graph 1 and Table 2. Body temperature exceeded the norm, and mean temperature was determined at $39.84{ }^{\circ} \mathrm{C}$ in Group I and $39.92{ }^{\circ} \mathrm{C}$ in Group II $(2.895$ and 2.982 points, respectively). The applied therapy did not induce significant changes in body temperature on day 3 , and mean temperature was determined at $39.43{ }^{\circ} \mathrm{C}$ (2.948 points) in Group I and $39.41{ }^{\circ} \mathrm{C}$ (2.873 points) in Group II. Significant changes in body temperature were noted on day 7 when the analyzed parameter was higher in Group I - $38.92{ }^{\circ} \mathrm{C}$ on average (1.981 points) and lower in Group II - $38.47^{\circ} \mathrm{C}(1.107$ points). On day 10 , body temperature was equalized in both groups, reaching $38.57^{\circ} \mathrm{C}$ on average in Group I ( 0.412 points) and $38.42{ }^{\circ} \mathrm{C}$ in group II ( 0.504 points). On day 15 , significant changes in body temperature were not noted relative to the previous measurements or between groups, and the average value of the parameter was determined at $38.41{ }^{\circ} \mathrm{C}$ in Group I ( 0.358 points) and $38.3^{\circ} \mathrm{C}$ in group II ( 0.303 points).

\section{Clinical symptoms - cough}

On day 1, more than 4 cough episodes per day with an accompanying gag reflex were observed in some dogs, and the average point score for this parameter was 3.894 points in Group I and 3.829 points in Group II. Cough severity decreased on successive days of the experiment and scored 3.725 points in Group I and 3.544 points in Group II on day 3. Cough severity and the gag reflex were significantly alleviated in Group II patients on days 7, 10 and 15 relative to Group I dogs, and the average score was 2.788 points in Group I and 2.106 points in Group II on day 7, 2.274 points in Group I and 0.857 points in Group II on day 10 , and 1.208 points in Group I and 0.211 points in Group II on day 15.

\section{Clinical symptoms - nasal/ocular discharge}

On day 1 , the average score for purulent nasal discharge and, in most cases, purulent ocular discharge was 3.657 points in Group 1 dogs and 3.709 points in Group II animals. On day

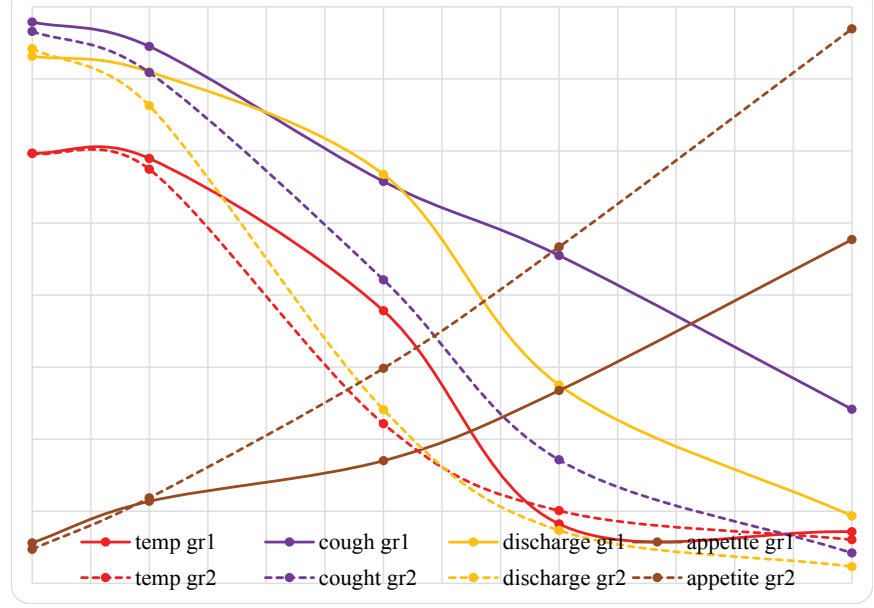

Graph 1: Severity of clinical symptoms in control group (gr1) and group receiving nebulization (gr2). 
Table 2: Severity of clinical symptoms of respiratory infection (mean \pm SEM) in control group dogs (Group I, $n=23$, and dogs receiving nebulization treatment $($ Group II, $n=23$ )

\begin{tabular}{|c|c|c|c|c|c|c|c|c|c|c|}
\hline & \multicolumn{5}{|c|}{ Group I } & \multicolumn{5}{|c|}{ Group II } \\
\hline Day & 1 & 3 & 7 & 10 & 15 & 1 & 3 & 7 & 10 & 15 \\
\hline \multirow[t]{2}{*}{ temp. $\left({ }^{\circ} \mathrm{C}\right)$} & 39.84 & 39.43 & $38.92^{b}$ & 38.57 & 38.41 & 39.92 & 39.41 & $38.47^{b}$ & 38.42 & 38.38 \\
\hline & \pm 0.153 & \pm 0.206 & \pm 0.378 & \pm 0.309 & \pm 0.543 & \pm 0.183 & \pm 0.211 & \pm 0.329 & \pm 0.374 & \pm 0.336 \\
\hline \multirow[t]{2}{*}{ temp. (points) } & 2.985 & 2.948 & $1.891^{\mathrm{b}}$ & 0.412 & 0.358 & 2.982 & 2.873 & $1.107^{b}$ & 0.504 & 0.303 \\
\hline & \pm 0.124 & \pm 0.141 & \pm 0.203 & \pm 0.209 & \pm 0.234 & \pm 0.113 & \pm 0.146 & \pm 0.278 & \pm 0.205 & \pm 0.199 \\
\hline \multirow[t]{2}{*}{ cough } & 3.894 & 3.725 & $2.788^{b}$ & $2.274^{b}$ & $1.208^{\mathrm{b}}$ & 3.829 & 3.544 & $2.106^{b}$ & $0.857^{b}$ & $0.211^{b}$ \\
\hline & \pm 0.106 & \pm 0.184 & \pm 0.207 & \pm 0.245 & \pm 0.122 & \pm 0.217 & \pm 0.235 & \pm 0.209 & \pm 0.142 & \pm 0.125 \\
\hline \multirow[t]{2}{*}{ discharge } & 3.657 & 3.549 & $2.837^{\mathrm{b}}$ & $1.376^{b}$ & $0.468^{\mathrm{b}}$ & 3.709 & 3.314 & $1.205^{b}$ & $0.367^{b}$ & $0.116^{b}$ \\
\hline & \pm 0.143 & \pm 0.167 & \pm 0.204 & \pm 0.154 & \pm 0.137 & \pm 0.138 & \pm 0.108 & \pm 0.131 & \pm 0.144 & \pm 0.102 \\
\hline \multirow[t]{2}{*}{ appetite } & 0,281 & 0,569 & $0,851^{\mathrm{b}}$ & $1.338^{b}$ & $2,385^{b}$ & 0,236 & 0,593 & $1.492^{\mathrm{b}}$ & $2,334^{b}$ & $3,847^{b}$ \\
\hline & \pm 0.211 & \pm 0.237 & \pm 0.201 & \pm 0.231 & \pm 0.152 & \pm 0.166 & \pm 0.249 & \pm 0.221 & \pm 0.151 & \pm 0.111 \\
\hline
\end{tabular}

astatistically significant at $p \leq 0.05$ (differences within groups); bStatistically significant at $p \leq 0.05$ (differences between groups).

Table 3: The results of arterial blood gas tests (mean \pm SEM) in control group dogs (Group I, $n=23$ ) and dogs receiving nebulization treatment $($ Group II, $n=23$ ).

\begin{tabular}{|c|c|c|c|c|c|c|}
\hline \multirow[b]{2}{*}{ Day } & \multicolumn{3}{|c|}{ Group I } & \multicolumn{3}{|c|}{ Group II } \\
\hline & 1 & 7 & 15 & 1 & 7 & 15 \\
\hline \multirow[t]{2}{*}{$\mathrm{pH}$} & 7.302 & 7.334 & 7.352 & 7.311 & 7.358 & 7.361 \\
\hline & \pm 0.051 & \pm 0.062 & \pm 0.059 & \pm 0.047 & \pm 0.071 & \pm 0.063 \\
\hline $\mathrm{pCO}_{2}$ & 54.784 & $51.018^{b}$ & $42.364^{a}$ & $53.284^{a}$ & $41.108^{b}$ & 39.819 \\
\hline $\mathrm{mmHg}$ & \pm 5.491 & \pm 4.826 & \pm 5.729 & \pm 6.199 & \pm 4.839 & \pm 4.543 \\
\hline $\mathrm{pO}_{2}$ & $90.204^{\mathrm{a}}$ & 95.067 & 97.264 & $90.816^{a}$ & 96.851 & 98.379 \\
\hline $\mathrm{mmHg}$ & \pm 2.738 & \pm 2.642 & \pm 2.409 & \pm 3.018 & \pm 2.688 & \pm 2.197 \\
\hline $\mathrm{HCO}_{3}^{-}$ & 23.702 & 22.517 & 20.079 & 24.011 & 20.216 & 19.803 \\
\hline $\mathrm{mmol} / \mathrm{l}$ & \pm 4.811 & \pm 4.144 & \pm 4.016 & \pm 5.037 & \pm 3.119 & \pm 4.391 \\
\hline $\mathrm{BE}$ & -4.109 & -3.876 & -2.687 & -3.997 & -3.016 & -2.276 \\
\hline $\mathrm{mmol} / \mathrm{l}$ & \pm 2.193 & \pm 2.358 & \pm 2.406 & \pm 2.242 & \pm 2.034 & \pm 2.671 \\
\hline $\mathrm{O}_{2} \mathrm{SAT}$ & 91.356 & 94.839 & 96.805 & 90.594 & 97.566 & 98.237 \\
\hline$\%$ & \pm 10.252 & \pm 9.364 & \pm 8.452 & \pm 10.251 & \pm 9.467 & \pm 9.193 \\
\hline $\mathrm{ctCO}_{2}$ & $29.899^{a}$ & 23.684 & 20.563 & $29.388^{a}$ & 20.801 & 19.879 \\
\hline $\mathrm{mmol} / \mathrm{l}$ & \pm 4.853 & \pm 5.405 & \pm 5.237 & \pm 6.416 & \pm 4.813 & \pm 5.025 \\
\hline
\end{tabular}

3 , a minor decrease in nasal and ocular discharge was noted with an average of 3.549 points in Group I and 3.314 points in Group II. An improvement was observed on successive days of the experiment. The average scores were significantly lower in Group II than in Group I, and they were determined at 2.837 points in Group I and 1.205 points in Group II on day 7, 1.376 points in Group I and 0.367 points in Group II on day 10, and 0.468 points in Group I and 0.116 points in Group II on day 15.

\section{Clinical symptoms - appetite}

On day 1 , the average score for appetite was 0,281 points in Group I dogs and 0,236 points in Group II animals. On day 3 , appetite levels were similar in both groups at 0,569 points in Group I and 0,593 points in Group II. Significant differences in appetite were observed between groups beginning on day 7 when the average score was 0,851 points in Group I, but 1.492 points in Group II. The most significant differences between groups were noted on day 10 at 1.338 points in Group I and 2,334 points in Group II. On day 15, the differences between groups were significant, at 2,385 points in Group I and 3,847 points in Group II.

\section{Blood gas parameters}

The results of arterial blood gas analyses are presented in Table 3. On day 1 , the measured parameters were similar and outside the normal range in both groups. Average blood $\mathrm{pH}$ was determined at 7.302 in Group I and 7.311 in Group II. On days 7 and 15, blood pH was closer to the normal range with an average of 7.334 in Group I and 7.358 in Group II on day 7, and 7.352 and 7.361, respectively, on day 15 . On day 1, partial pressure of carbon dioxide $\left(\mathrm{pCO}_{2}\right)$ was determined at 54.784 $\mathrm{mmHg}$ in Group I and $53.284 \mathrm{mmHg}$ in Group II (significant difference relative to successive measurements). On day 7 , $\mathrm{pCO}_{2}$ differed significantly between groups at $51.018 \mathrm{mmHg}$ in Group I and $41.108 \mathrm{mmHg}$ in Group II. On day 15, $\mathrm{pCO}_{2}$ in Group I was significantly lowest relative to the previous measurements at $42.364 \mathrm{mmHg}$. In Group II, the value of the above parameter reached $39.819 \mathrm{mmHg}$ on day 15 .

On day 1 , partial pressure of oxygen $\left(\mathrm{pO}_{2}\right)$ was significantly lowest in both groups relative to successive days of the experiment at $90.204 \mathrm{mmHg}$ in Group I and $90.816 \mathrm{mmHg}$ in Group II. Average $\mathrm{pO}_{2}$ reached $95.067 \mathrm{mmHg}$ in Group I and $96.851 \mathrm{mmHg}$ in Group II on day 7, and $97.264 \mathrm{mmHg}$ and $98.379 \mathrm{mmHg}$, respectively, on day 15. The concentration of bicarbonate ions $\left(\mathrm{HCO}_{3}^{-}\right)$in arterial blood decreased throughout the experiment in both groups. The average value of $\mathrm{HCO}_{3}$ - was determined at $23.702 \mathrm{mmol} / \mathrm{l}$ in Group I and $24.011 \mathrm{mmol} / \mathrm{l}$ in Group II on day 1, $22.517 \mathrm{mmol} / \mathrm{l}$ and $20.216 \mathrm{mmol} / \mathrm{l}$, respectively, on day 7 , and $20.079 \mathrm{mmol} / \mathrm{l}$ and $19.803 \mathrm{mmol} / \mathrm{l}$, respectively, on day 15 . Significant 
differences in base excess/deficit (BE) were not observed between groups or experimental days. The average value of this parameter was determined at $-4.109 \mathrm{mmol} / \mathrm{l}$ in Group I and $-3.997 \mathrm{mmol} / \mathrm{l}$ in Group II on day $1,-3.876 \mathrm{mmol} / \mathrm{l}$ in Group I and $-3.016 \mathrm{mmol} / \mathrm{l}$ in Group II on day 7, and -2.687 $\mathrm{mmol} / \mathrm{l}$ in Group I and $-2.276 \mathrm{mmol} / \mathrm{l}$ in Group II on day 15 . Oxygen saturation $\left(\mathrm{O}_{2} \mathrm{SAT}\right)$ increased on successive days of the experiment, and a higher increase was noted in Group II. The average value of this parameter was determined at $91.356 \%$ in Group I and $90.594 \%$ in Group II on day 1, 94.839\% and $97.566 \%$, respectively, on day 7 , and $96.805 \%$ and $98.237 \%$, respectively, on day 15 . Total carbon dioxide content in blood $\left(\mathrm{CtCO}_{2}\right)$ was significantly highest in both groups on day 1 relative to successive days of the experiment, and it was determined at $29.899 \mathrm{mmol} / \mathrm{l}$ in Group I and $29.388 \mathrm{mmol} / \mathrm{l}$ in Group II. On day 7, the above parameter decreased to 26.684 $\mathrm{mmol} / \mathrm{l}$ in Group I and $20.801 \mathrm{mmol} / \mathrm{l}$ in Group II. On day 15, the value of $\mathrm{ctCO}_{2}$ decreased further to $20.563 \mathrm{mmol} / \mathrm{m}$ in Group I and $19.879 \mathrm{mmol} / \mathrm{l}$ in Group II.

\section{Discussion}

The severity of symptoms associated with respiratory tract infection, including elevated body temperature, frequent cough with an accompanying gag reflex, serous or serous-purulent nasal and ocular discharge, decrease or loss of appetite, was similar in all dogs at the beginning of the experiment. The above symptoms were caused by mixed infections with CPiV, CHV, CaV2 and Bordetella bronchiseptica, which were also identified as causative agents of canine respiratory tract infections in a study conducted by Schulz, et al. [22] in southern Germany.

Wet cough and abundant respiratory discharge point to the accumulation of respiratory secretions which, when accompanied by mucosal edema and inflammatory cell infiltration, lead to airway constriction and thickening of the blood-air barrier in capillaries that surround pulmonary alveoli. According to Eleanor, [6], Orellana, et al. [4] and Rahman and Mac Nee, [5], the above decreases the amount of air entering the lungs and inhibits gas exchange in pulmonary alveoli. In our study, higher carbon dioxide levels and oxygen deficiency contributed to respiratory acidosis which was further stimulated by intense metabolic activity during fever. Acidosis and hypoxia intensify the depressive effect of fever and together with respiratory obstruction, they contribute to a decrease or complete loss of appetite, general fatigue and apathy. Such symptoms were observed in all dogs on the first day of the experiment. They were also reported by the owners. These processes disrupt metabolic activity [23] and if persistent, they can lead to emaciation and negative treatment outcomes [7]. Similar results were reported by Nagy, et al. [24], in cattle with bronchopneumonia.

Conventional treatments for respiratory tract infections rely on drugs with anti-inflammatory, anti-infective and immuno stimulating properties which do not directly resolve gas exchange abnormalities. Lung ventilation can be improved through nebulization which promotes the liquidation of mucus and its evacuation from the bronchial tree. In this study, nebulization therapy was applied in Group II, where it reduced the severity of respiratory infection symptoms and improved the overall condition of all animals. Beginning on day 7 , a significant improvement in the following clinical parameters was observed in Group II dogs relative to Group I animals: restoration of normal body temperature, lower cough frequency, decrease or elimination of nasal and/or ocular discharge, improved appetite, and improvement in the patients' overall condition. The above changes were mirrored by the results of arterial blood gas tests. A greater decrease in the partial pressure of carbon dioxide and total content of carbon dioxide, and a greater increase in the partial pressure of oxygen and oxygen saturation were observed in dogs receiving nebulization treatment relative to Group I dogs. Normal $\mathrm{BE}$ values were restored more rapidly in Group II patients. These changes testify to improved gas exchange [25], which promotes the liquidation of mucus and its evacuation from the respiratory tract. The beneficial effects of nebulization treatment in human patients were described by Bennett, et al. [13] and Main, et al. [14] who combined nebulization with physical therapy to facilitate mucus clearance from the bronchi. In our experiment, percussion was performed to loosen and evacuate mucus. Adverse responses to nebulization were not observed during or after treatment. Percussion intensified mucus clearance in Group II dogs, and it improved the quality of breathing and the patients' overall condition.

Our research were carry out on dogs of various breeds, including brachycephalic ( 2 mix breed and 3 pugs), but we don't estimate important differences between this and others dogs. According to Aroma, et al. Darcy, et al. Davs, et al. Fawcett, et al. and Honey [26-30] brachycephalic dogs suffer for BOAS, pneumonia, soft palatine diseases, thermoregulation problems etc, and that should be aim of the future investigation.

The objective of this study was to evaluate the efficacy of nebulized only sodium chloride solution in dogs. In animal clinic treatment [31,32] and human medicine [1,17,19-21] there are used many different pharmacological substances, for example steroids, antibiotics, mucolytic etc. Using this kind of drugs by nebulization should be potential future directions of investigations.

\section{Conclusion}

A comparison of the patients' clinical status and the results of arterial blood gas tests in both groups indicates that the administration of nebulized $0.9 \% \mathrm{NaCl}$ speeds up convalescence and improves the wellbeing of animals undergoing treatment for respiratory tract infections. Our findings also indicate that arterial blood gas tests are highly useful for monitoring the condition of the canine respiratory system. 


\section{Acknowledgement}

This piece of work was partially or fully funded by Department of Internal Diseases with Clinic, Faculty of Veterinary Medicine, University of Warmia and Mazury in Olsztyn, Oczapowskiego 14, 10-957 Olsztyn, Poland and Department of Microbiology and Clinical Immunology, Faculty of Veterinary Medicine, University of Warmia and Mazury in Olsztyn, Oczapowskiego 13, 10-957 Olsztyn, Poland.

\section{References}

1. Shariati M, Willaert W, Ceelen W, De Smedt SC, Remaut K. Aerosolization of nanotherapeutics as a newly emerging treatment regimen for peritoneal carcinomatosis. Cancers (Basel). 2019; 11: E906: PubMed: https://www.ncbi.nlm.nih.gov/pubmed/31261685

2. Sudo $E$, Boyd WA, King M. Effects of dextran sulfate on tracheal mucociliary velocity in dogs. J Aerosol Med. 2000; 13: 87-96.

PubMed: https://www.ncbi.nlm.nih.gov/pubmed/11010598

3. MochizukiM,YachiA,OhshimaT,OhuchiA,IshidaT.Etiologicstudy ofupper respiratoryinfections ofhouseholddogs. JVetMedSci.2008;70:563-569. PubMed: https://www.ncbi.nlm.nih.gov/pubmed/18628596

4. Orellana $\mathrm{M}$, Rodrigo $\mathrm{R}$, Thielemann $\mathrm{L}$, Guajardo V. Bile duct ligation and oxidative stress in the rat: effects in liver and kidney. Comp Biochem Physiol C Toxicol Pharmacol. 2000; 126: 105-111.

PubMed: https://www.ncbi.nlm.nih.gov/pubmed/11050682

5. Rahman I, MacNee W. Oxidative stress and regulation of glutathione in lung inflammation. Eur Respir J. 2000; 16: 534-554. PubMed: https://www.ncbi.nlm.nih.gov/pubmed/11028671

6. Eleanor $\mathrm{CH}$. Small Animal Internal Medicine, Blood Gas Analysis. 4th ed. $2009 ; 267-283$.

7. Yin ZJ, Jin FG, Xie YH. Influence of gas inhalation with different oxygen contents on the changes of blood gas in arterial blood and cerebrospinal fluid of dogs in plateau. Chin J Clin Rehab. 2005; 9: 102-104.

8. Kiers HD, Scheffer GJ, Van Der Hoeven JG, Eltzschig HK, Pickkers P, et al. Immunologic consequences of hypoxia during critical illness. Anesthesiology. 2016; 125: 237-249.

PubMed: https://www.ncbi.nlm.nih.gov/pubmed/27183167

9. Tomkiewicz RP, App EM, De Sanctis GT, Coffiner M, Maes $P$, et al A comparison of a new mucolytic $\mathrm{N}$-acetylcysteine I-lysinate with $\mathrm{N}$-acetylcysteine: Airway epithelial function and mucus changes in dog. Pulm Pharmacol. 1995; 8: 259-265.

PubMed: https://www.ncbi.nlm.nih.gov/pubmed/8819180

10. Bexfield NH, Foale RD, Davison LJ, Watson PJ, Skelly BJ, et al. Management of 13 cases of canine respiratory disease using inhaled corticosteroids. J Small Anim Prac. 2006; 47: 377-382.

PubMed: https://www.ncbi.nlm.nih.gov/pubmed/16842273

11. Boyle TE, Hawkins EC, Davis JL, Robertson ID. Failure of nebulized irritant, acidic, or hypotonic solutions or external mechanical stimulation of the trachea to consistently induce coughing in healthy, awake dogs. Canad J Vet Res. 2011; 75: 228-232.

PubMed: https://www.ncbi.nlm.nih.gov/pubmed/22211000

12. Dicpinigaitis PV, Morice AH, Birring SS, McGarvey L, Smith JA, et al. Antitussive drugs-past, present, and future. Pharm Rev. 2014; 66: 468512. PubMed: https://www.ncbi.nlm.nih.gov/pubmed/24671376

13. Bennett WD, Wu J, Fuller F, Balcazar JR, Zeman KL, et al. Duration of action of hypertonic saline on mucociliary clearance in the normal lung. J Appl Physiol (1985). 2015; 118: 1483-1490.

PubMed: https://www.ncbi.nlm.nih.gov/pubmed/25911685
14. Main E, Grillo L, Rand S. Airway clearance strategies in cystic fibrosis and non-cystic fibrosis bronchiectasis. Semin Respir Crit Care Med. 2015; 36: 251-266.

PubMed: https://www.ncbi.nlm.nih.gov/pubmed/25826592

15. Fernandes CA, Vanbever R. Preclinical models for pulmonary drug delivery. Expert Opin Drug Deliv. 2009; 6: 1231-1245.

PubMed: https://www.ncbi.nlm.nih.gov/pubmed/19852680

16. Chow KE, Tyrell D, Yang M, Abraham LA, Anderson GA. Scintigraphic Assessment of Deposition of Radiolabeled Fluticasone Delivered from a Nebulizer and Metered Dose Inhaler in 10 Healthy Dogs. J Vet Int Med. 2017; 31: 1849-1857.

PubMed: https://www.ncbi.nlm.nih.gov/pubmed/28961322

17. Babaei H, Dabiri S, Pirkashani L.M, Mohsenpour H. Effects of salbutamol on the treatment of transient tachypnea of the newborn. Iran J Neon Open Acc. 2019; 10: 42-49.

18. Chandel A, Goyal AK, Ghosh G, Rath G. Recent advances in aerosolised drug delivery. Biomed Pharmacother. 2019; 112: 108601. PubMed: https://www.ncbi.nlm.nih.gov/pubmed/30780107

19. Lim BA, Lopez A, Buensalido JA. Refractory Burkholderia cepacia bacteraemia from a consolidation pneumonia lasting more than 7 weeks, successfully treated with systemic. BMJ Case Rep. 2019; 12. PubMed: https://www.ncbi.nlm.nih.gov/pubmed/31377717

20. Lin Y, Chang RYK, Britton WJ, Morales S, Kutter E, et al. Inhalable combination powder formulations of phage and ciprofloxacin for $\mathrm{P}$. aeruginosa respiratory infections. Eur J Pharm Biopharm. 2019; 142: 543-552.

PubMed: https://www.ncbi.nlm.nih.gov/pubmed/31398437

21. Lvovschi VE, Joly J, Lemaire $N$, Maignan $M$, Canavaggio $P$, et al Nebulized versus intravenous morphine titration for the initial treatment of severe acute pain in the emergency department: Study protocol for a multicenter, prospective randomized and controlled trial, CLIN-AEROMORPH. Trials Op Acc. 2019; 20.

22. Schulz BS, Kurz S, Weber K, Balzer HJ, Hartmann K. Detection of respiratory viruses and Bordetella bronchiseptica in dogs with acute respiratory tract infections. Vet J. 2014; 201: 365-369. PubMed: https://www.ncbi.nlm.nih.gov/pubmed/24980809

23. Romano TG, Correia MDT, Mendes PV, Zampieri FG, Maciel AT, et al. Metabolic acid-base adaptation triggered by acute persistent hypercapnia in mechanically ventilated patients with acute respiratory distress syndrome. Rev Bras Ter Intensiva. 2016; 28: 19-26. PubMed: https://www.ncbi.nlm.nih.gov/pubmed/27096672

24. Nagy O, Seidel H, Paulíková I, Mudroň P, Kováč G. Use of blood gases and lactic acid analyses in diagnosis and prognosis of respiratory diseases in calves. Bul Vet Inst Pulawy. 2006; 50: 149-152.

25. Pomianowski A, Kuleta Z, Stopyra A, Sobiech P. Badania parametrów równowagi kwasowo-zasadowej we krwi tętniczej, żylnej i włośniczkowej psów zdrowych. Med Wet. 2004; 60: 519-522.

26. Aromaa M, Lilja-Maula L, Rajamaki MM. Assessment of welfare and brachycephalic obstructive airway syndrome signs in young, breeding age French Bulldogs and Pugs, using owner questionnaire, physical examination and walk tests. Anim Welf. 2019; 28: 287-298.

27. Darcy HP, Humm K, Ter Haar G. Retrospective analysis of incidence, clinical features, potential risk factors, and prognostic indicators for aspiration pneumonia in three brachycephalic dog breeds. J Am Vet Med. 2018; 253: 869-876.

28. Davis MS, Cummings SL, Payton ME. Effect of brachycephaly and body condition score on respiratory thermoregulation of healthy dogs. J Am Vet Med Ass. 2017; 251: 1160-1165.

PubMed: https://www.ncbi.nlm.nih.gov/pubmed/29099251 
29. Fawcett A, Barrs V, Awad M, Child G, Brunel L, et al. Consequences and management of canine brachycephaly in veterinary practice: perspectives from Australian veterinarians and veterinary specialists. Anim Open Acc. 2019; 9: 3.

PubMed: https://www.ncbi.nlm.nih.gov/pubmed/30577619

30. Honey L. Future health and welfare crises predicted for the brachycephalic dog population. Vet Rec. 2017; 181: 550.

31. Chow KE, Tyrell D, Yang M, Abraham LA, Anderson GA. Scintigraphic
Assessment of Deposition of Radiolabeled Fluticasone Delivered from a Nebulizer and Metered Dose Inhaler in 10 Healthy Dogs. J Vet Int Med. 2017; 31: 1849-1857.

PubMed: https://www.ncbi.nlm.nih.gov/pubmed/28961322

32. Dos Santos Filho M, Hainfellner D, Do Amaral Mendononca D, De Oliveira Folha MRV, Alberigi BRS, et al. Nebulization with sodium chloride solution $(0,9 \%)$ in the treatment of chronic canine bronchitis. Ac Vet Bras. 2017; 11: 90-92. 